\title{
THE POTENTIAL OF LOCATION-BASED GAMIFICATION APPS FOR PROMOTING SOFIA AS A TOURIST DESTINATION
}

\author{
Sonia Mileva ${ }^{\mathrm{a}}$ (D), Mariana Assenova ${ }^{\mathrm{b}}$ (D), Emil Petrov ${ }^{\mathrm{c}}$, Veneta Gyaurova ${ }^{\mathrm{d}}$ \\ a Sofia University "St. Kliment Ohridski", Faculty of Economics and Business Administration, Department of Industrial Economics \\ and Management; https://orcid.org/0000-0002-5636-874X; e-mail: smileva@feb.uni-sofia.bg \\ b Sofia University "St. Kliment Ohridski", Faculty of Geology and Geography, Geography of Tourism Department; \\ https://orcid.org/0000-0001-6639-5816; e-mail: mariana@gea.uni-sofia.bg \\ ' Sofia University "St. Kliment Ohridski”, Faculty of Geology and Geography, Geography of Tourism Department; \\ e-mail: emil@gea.uni-sofia.bg \\ d Sofia University “St. Kliment Ohridski”; e-mail: veni.nikolova@gmail.com
}

\begin{abstract}
The main aim of the research is to identify the potential of location-based gamification apps for promoting tourist destinations. The specific goal is to investigate and evaluate the existing gamified apps for Sofia and reveal their potential as a marketing tool for enhancing the capital as a tourist destination. The study is based on a literature review on the topic and desk research of the available location-based gamification apps for promoting Sofia as a tourist destination thus allowing a comparative analysis of the main attributes of the gamified apps to be made. The qualitative research technique of using key informants is also applied, providing an expert source of information and a deeper insight into current and potential practices in the research area and their effectiveness. The results indicate that this has the greatest potential for further engagement of users and the co-creation of products and services as well as for raising awareness of the destination. The main limitations are related to the fact that they are a relatively new and little-known marketing tool in the field of tourism, and this predetermines a lack of sufficient knowledge and experience for their use for promotional purposes.
\end{abstract}

\section{KEYWORDS}

gamification, app, tourism, destination, Sofia

\section{ARTICLE INFORMATION DETAILS}

Received:

1 December 2020

Accepted:

13 April 2021

Published:

11 June 2021

This article is funded by Research Project - "Gamification in Tourism - opportunities and threats", funded by Sofia University Research Fund 2020.

\section{INTRODUCTION}

Recently gamification has entered as a marketing tool with great success for enhanced engagement and dynamic interaction with consumers (Seaborn, Fels, 2015). As a concept, gamification is defined as the "use of game design element and game thinking in a non-gaming context" (Deterding, Dixon, Khaled, Nacke, 2011, p. 5).

In the field of tourism, gamification as a theory has only recently captured researchers' attentions and is seen as a powerful acceleration tool for consumer loyalty (Zichermann, Cunningham, 2011) whereas in fact it is a new concept for an old phenomenon (Swacha, Ittermann, 2017). In the tourism sector gamification is not unknown and has been applied to building loyalty programs for consumer engagement $(\mathrm{Xu}$, Weber, Buhalis, 2014), nevertheless only a limited number of publications consider a gamification app at destination level.

Gamification in tourism has been approached in different ways and six areas of impact are identified: raising of awareness, enhanced tourist experience, 
engagement, improved customer loyalty, entertainment and employee management (Xu, Weber, Buhalis, 2014). Taken into consideration as well are sustainability effects (economic, social and environmental) and the relationship between major stakeholders in tourism: tourism organizations, tourists, employees and the community (Negruşa, Toader, Sofică, Tutunea, Rus, 2015). From a tourist perspective value co-creation and enriched tourist experiences (social, emotional and immersive) are the major areas of gamification influences (Neuhofer, Buhalis, Ladkin, 2012; Xu, 2012). The impacts of gamification apps for pre-, during and post-travelling (Weber, 2014) are also explored.

In this article we consider technologically-mediated gamification apps. Usually they can be applied in the three major phases of the tourist visiting process: before, on-site and after. Before trip gamification apps aim to attract, raise interest and create awareness, but it is at the destination level itself that tourist experience is formed and shaped. That is why in this article only onsite, location-based apps will be considered. The main idea is to investigate and evaluate the communication impacts on tourists, already arrived on site and this is why the authors approach location-based gamification apps at destination level and in particular for Sofia, the capital of Bulgaria.

Tourists' motivation and expectations are becoming extremely complex in their search of meaningful experiences, entertainment and learning, with game design and game elements then being related to "selfdetermination theory" and intrinsic motivation (Deci, Richard, 1985; Deterding, Dixon, Khaled, Nacke, 2011). Three innate needs for intrinsic motivation are identified: relatedness (connectivity), competence (effective in a given environment) and autonomy (control of one's own life), and are all fundamental for successful gamification (Groh, 2012).

Entertainment and the power of gamification are based both on extrinsic and intrinsic gaming elements. The extrinsic elements are achievements, badges, rewards, gifting, feedback and reinforcement, pattern recognition, collecting etc (Deterding, Dixon, Khaled, Nacke, 2011; Zichermann, Cunningham, 2011), while intrinsic elements are relation groups, messages, blogs, chats; competence feedback, progressive bar levels, leader board; autonomy profiles, avatars, privacy control, notification control (Deterding, Dixon, Khaled, Nacke, 2011; Schell, 2008; Xu, Weber, Buhalis, 2014).

From a tourist behavior perspective, relatedness can be seen as an attempt to connect with others, e.g. local communities, travelling gurus and other meaningful communities for tourism destinations or interests; taking part and creating meaningful stories or co-creating travel experience; connecting personal goals with the destination. Competence links to interesting challenges, clearly location-based, visual goals and fun learning, or discovering at one's personal pace. Autonomy needs are matched with contemporary tourist individual needs, interests and behavior.

Tourism by definition is an expression of free will, as it is in gamification apps as well. Recent developments concerning COVID-19 enhance even more social distances when travelling at one's own pace and tempo, according to personal interests and preferred activities. Thus, location-based gamification apps satisfy tourist needs and motivation combining not only engagement, but also experiential co-creation and an individual pace of visiting, discovering and learning about the destination.

\section{RESEARCH METHODS}

In the context described the main aim of the research is to identify the potential of gamification apps for promoting tourist destinations. The specific goal is to investigate and evaluate existing gamification apps for Sofia and reveal their potential as a marketing tool for enhancing the capital as a tourist destination.

The study is based on a literature review on the topic, as well as on desk research of international experience and the available apps for promoting Sofia as a tourist destination. This allows a comparative analysis of the main attributes of the gamified apps to be made. The research as undertaken in the period 26.05.202021.06.2020. The data about the available mobile apps for Sofia was collected via desk research on iOS and Android platforms, and the respective mobile app stores for end users. For Sofia, a useful source for desk research was the information available from National "Culture" Fund under the "Cultural Heritage" program, and in particular the "Cultural Industries and Cultural Tourism" project enhancing innovations and gamification as a tool for tourism development, all financially supported by Sofia municipality.

To fulfill the purpose of the study the key informant technique (Marinov, 2005; Marshal, 1996) was applied to utilize expert sources of information to provide a deeper insight into current and potential practices in the research area and their effectiveness. This technique is chosen in order to obtain qualitative data in a relatively short period of time. In selecting the key informants, five eligibility characteristics are considered, namely, formal role and position in the community, knowledge, willingness, communicability and impartiality. A pilot testing of the questionnaire was undertaken among the twelve key informants selected to represent tourism associations and companies, cultural institutions, Sofia destination management organizations, governmental bodies, the IT sector and academia.

As a qualitative research method, interviews with key informants are primarily intended to gather "soft" 
information (opinions, assessments, attitudes) but they can also provide "hard" quantitative information (facts and data) through the use of pre-defined tools (semi-structured questionnaire, pre-defined answers, rating scales, ranks, etc.) allowing easy quantification of some of the results (Marinov, 2012). To avoid the main disadvantage of the technique, the reliability of the obtained information, and to further ensure "triangulation" (verification) of the results, secondary quantitative data from the apps are systemized, analyzed and assessed. A detailed survey of tourist demand for gamification apps is envisaged once the sector recovers from the coronavirus pandemic.

A semi-structured questionnaire was developed by the authors and its design was a challenge owing to the lack of tourists and the limited experience with gamification apps in Sofia. The questionnaire consisted of 19 questions, of which twelve were closed and seven open. The closed questions were intended to outline the experience of the key informants and to identify the degree of acceptance of predefined statements regarding the most important elements and characteristics of gamification apps for Sofia.

There have been numerous studies of tourist demand for Sofia as a destination in the last ten years, but in all cases apps are considered only as a source of information and gamification apps are not specifically differentiated (Marinov, Dogramadjieva, Assenova, Petkova, Baikov, 2015). For these reasons, research questions about marketing potential were derived from academic publications presenting the marketing potential of locationbased gamification apps at destination level. The potential marketing effects are identified to outline the framework for investigation and discussion of results.

A hybrid survey approach was applied to avoid long face-to-face interviews. The questionnaire was uploaded on Google Forms to be completed by the invited key informants, afterwards they were contacted by phone to further discuss specified issues. The survey was conducted in the period June $30^{\text {th }}-J u l y ~ 10^{\text {th }} 2020$. The key themes were predefined based on the literature review and were subjected to quantitative assessment while the transcribed free comments were analyzed using iterative-inductive thematic analysis (King, 2004, after: Chapman, Light, 2016). The initial statements were coded into thematic groups which were subsequently further grouped by main topic, thus expanding on the predefined thematic areas.

\section{RESULTS AND DISCUSSION}

At a destination level, gamification apps are not a very popular marketing tool, with some exceptions. Some destination management organizations have designed their own games such as VisitNorway for Holmenkollen Ski Jump (2006), Tourism Ireland (2011), Brasil Quest Game (2012), Thailand and China (Corrêaa, Kitanoa, 2015; Xu, Weber, Buhalis, 2014). These gamified apps are seen as a marketing tool for promotion and shaping tourist behavior using game mechanics and design elements to measure, influence and reward target behaviors (Maan, 2013).

Apart from these, there are many successful gamification apps developed by independent start-up companies in the field of innovative digital marketing. Such a successful example is Nexto (Slovenia) - a gamification mobile app for promoting cultural and historical sites, integrating them into gamified storylines at the destination level (see. Nexto, 2021). The app is a readymade solution for tourist sites and organizations aiming to promote a destination and to create engaging experiences in an augmented reality environment. The same app is used in Croatia, Austria, New Zealand and other places and was a winner at Booking.com Booster Lab for 2017 and "Best practice in digitalization" by the "European Capital for Smart Tourism" initiative for 2019

Questo (Romania), launched in 2017, is another mobile app based on an interactive quiz about interesting and authentic tourist sites. Users of the app become "discoverers" by following riddles, hints, clues and questions (see About Questo, 2021). The app was a huge success receiving a UNWTO award for innovative startups in 2019. Among success factors is the combination of a tour guide service and gamification, targeted to the new generation of tourists (millennials). Proof of the success of the app are awards from Booking.com Booster Lab for 2018, eTravel Awards 2017 and others.

Secret City Trails (Portugal) is a gamification platform for preserving and promoting the authenticity of cities through the power of play (see Secretcitytrails, 2021). Created by young entrepreneurs as an innovative start-up, based in Lisbon in Portugal and partnering with local game creators from all over Europe, the gamification app allows users to discover hidden and off-the-beaten path places by solving a trail of riddles at a destination. The platform is supported by accelerators from Beta-i, Startup Lisboa, FutureNow, Altice, Booking.com.

For Sofia as a tourism destination the results of the research show the following types of mobile apps published on the official Sofia tourist site (www. visitsofia.bg): guides - Farrol City Guides, Pocket guide; VisitSofia (2019) - the official app using realtime location to direct users to the nearest sites of tourist interest.

Apart from the official site on the Google mobile app store (Google Play) there are more than 20 mobile apps available for Sofia which run on the Android operating system and can be downloaded and used when visiting the city, namely Sofia Travel Guide (Offline), Sofia City 
Directory, Reinvent Sofia, Sofia City Guide, Sofia Map and Walks, Sofia Offline Map and Travel Guide, Sofia SmartGuide - Audio Guide \& Offline Maps, Sofia Tour Guide, Sofia Travel \& Explore, Offline Tourist Guide, Sofia Travel Guide, Sofia Amenities, etc. A popular app is Sofia CulTOUR Mobile free App which is an interactive platform that provides information about the most interesting and popular cultural events, cultural and historical landmarks, museums, galleries and routes around the sights of Sofia. Similar to this is the gamification app Reinvent Sofia, which is an interactive map of the city that includes various landmarks from different historical periods with the aim of putting all the places and themes in correct historical sequence.

The research revealed that none of them can be identified as location-based gamification apps for promoting Sofia as a tourist destination, with the exception of Sofia's Centre: 7 millennia of secrets and Ancient Serdica Riddles. The first one is a private initiative, a part of the Secret Cities Trail platform. The second, Ancient Serdica Riddles, has been developed by an NGO, starting as a project funded by the "Cultural Heritage" program "Cultural Industries and Cultural Tourism" module, supported by Sofia municipality and Sofia city museum. A comparative analysis of these two gamified apps has been made and the following distinctive attributes are outlined: 1) scope and thematic axis 2) extrinsic motivation and 3) gamification elements (Table 1).

What is common in these two is the use of game elements such as solving riddles along a designated tour/trail/route, and as such both apps are related to "self-determination theory" and intrinsic motivation (Deci, Richard, 1985; Deterding, Dixon, Khaled, Nacke, 2011). The innate needs identified for triggering intrinsic motivation are relatedness (connectivity), competence (effective in given environment) and autonomy (control of one's own life) for Sofia's Centre: 7 millennia of secrets and competence and autonomy for Serdica Riddles. Whilst the first is focused on the exploration of specific cultural heritage sites such as the archaeological remains from a certain historical period (Late Antiquity) within the boundaries of the ancient city, the second represents the main tourist attractions from different historical periods within the present city center.

The Serdica Riddles app has been officially published and was available from 20.05.2020. In the period 20.058.07.2020 a total of 344 users from around the world have installed it on mobile devices and tablets, with a level below $47 \%$ for de-installations. By nationality, the main users are from Bulgaria (40\%), Austria (11\%), Great Britain (9\%), the Netherlands (9\%), Poland (8\%), Germany $(7 \%)$ - traditional markets for Sofia with regular flights. About Secret City Trails there is no avaliable data for comparison.

Almost all key informants (90\%) point out that currently the location-based gamification apps with a tourist orientation discussed are not very popular among Sofia's visitors, however $90 \%$ of those interviewed agree that gamified apps add value to the tourist experience in the destination.

The results of the survey indicate that selected key informants envisage moderate to high potential for location-based gamification apps for promoting Sofia as a tourist destination (Fig. 1), as the identified aspects of potential marketing effects are evaluated between 3.3 and 3.9 on a 5 -degree scale ( 1 - the lowest and 5 - the highest). The highest is the potential for greater engagement of users and co-creation of products and services (3.9), as well as for raising awareness of the destination (3.8). Fairly high is considered to be the potential for creating positive attitudes (3.6) and an increase in brand awareness (3.6). The lowest turns out to be the potential for forming public opinion (3.3) and for impacting the behavior of users (3.3).

The main reason for the moderate optimism is the low level of awareness of existing location-based gamification apps for Sofia as a tourist destination: altogether $58 \%$ declare personal expericence with them, but only $42 \%$ are familiar with and have personally tried at least one of the existing apps for Sofia in particular. The better known app is Serdica Riddles (80\%), compared

Table 1. Comparative analysis of location-based gamification apps for Sofia as a tourist destination

\begin{tabular}{|l|l|l|l|}
\hline \multicolumn{1}{|c|}{ App } & \multicolumn{1}{|c|}{ Scope and thematic axis } & \multicolumn{1}{c|}{ Extrinsic motivation } & \multicolumn{1}{c|}{ Gamification elements } \\
\hline Ancient Serdica Riddles & $\begin{array}{l}\text { Promotion of archaeological } \\
\text { heritage sites and museum } \\
\text { exhibits from the Late } \\
\text { Antiquity within the } \\
\text { boundaries of the Ancient } \\
\text { Serdica complex in the city } \\
\text { of Sofia }\end{array}$ & $\begin{array}{l}\text { Based on collecting coins by } \\
\text { solving riddles and receiving } \\
\text { a badge reward at the end of } \\
\text { the game when a minimum } \\
\text { number of coins have been } \\
\text { collected }\end{array}$ & $\begin{array}{l}\text { Self-guided tour with } \\
\text { Serdica }\end{array}$ \\
\hline $\begin{array}{l}\text { Sofia's Centre: } 7 \text { millennia } \\
\text { of secrets (Secret city trails) }\end{array}$ & $\begin{array}{l}\text { Representing the main tourist } \\
\text { attractions from different } \\
\text { historical periods within the } \\
\text { city center of Sofia }\end{array}$ & $\begin{array}{l}\text { Based on sharing the best } \\
\text { adventure photos using the } \\
\text { tag \#secretcitytrails and } \\
\text { receiving a free game }\end{array}$ & $\begin{array}{l}\text { Self-guided tour with } \\
\text { attractions }\end{array}$ \\
\hline
\end{tabular}

Source: authors based on Serdica Riddles (2021), Discover Sofia (2021). 


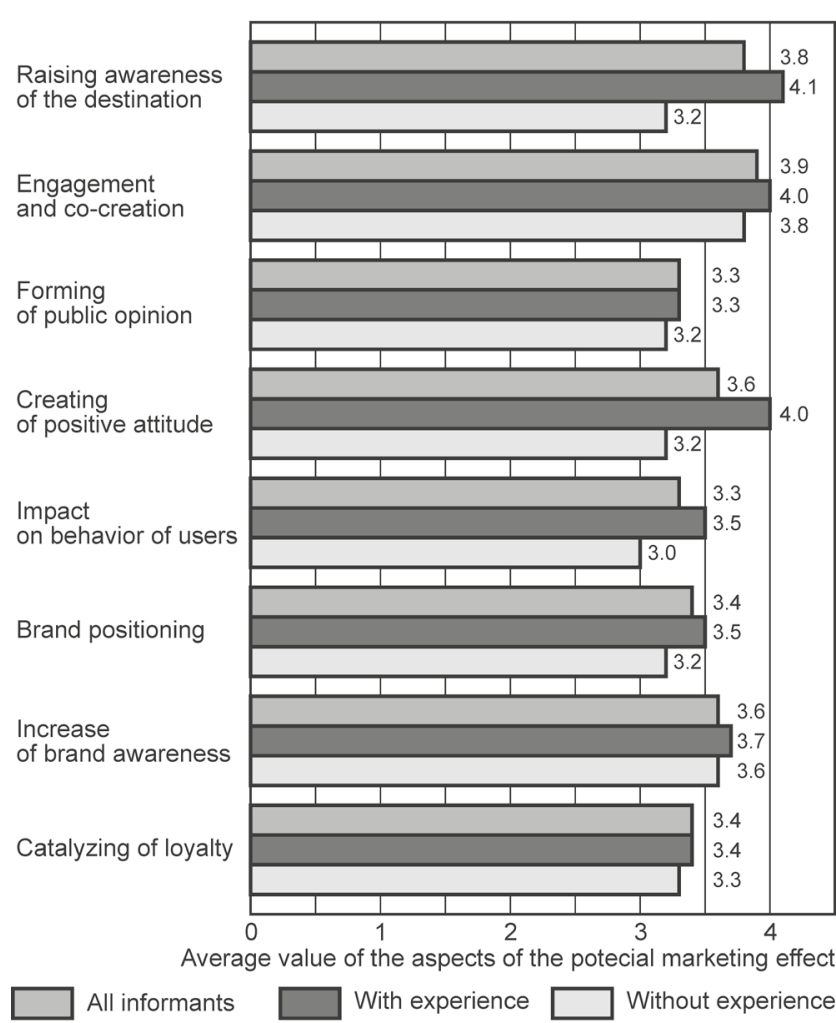

Figure 1. Evaluation of the potential marketing effect Source: authors

to Secret City Trails (20\%), which is probably due to the recently launched Facebook ad campaign for Serdica Riddles.

Informants with personal experience tend to be more inclined to perceive a higher marketing potential, especially in terms of raising awareness of the destination (4.1), the engagement and co-creation of services and products (4.0) and the creation of positive attitude towards the destination (4.0). They also see higher potential in the use of gamified apps for the brand positioning of the city.

From a marketing perspective, the use of locationbased gamification apps envisaged by local key informants coincides with the experience and potential outlined in other destinations. Those interviewed agree that their main advantage, as pointed out by $\mathrm{Wu}$ and Stilwell (2018), is the need for physical presence in the destination and it is also stated that they could be used to attract visitors from market segments that would not visit for other purposes. Thus, the opportunity for a competitive offering in segments that are not currently the focus of destination marketing is foreseen. The innovative approach would be attractive and in compliance with new consumer needs and new forms of travel.

In general the informants comment on gamification apps mainly as a promotional tool and the opportunity to expand the channels for providing information and promoting the destination, including feedback and data collection. In their opinion they could lead to raising awareness of the destination $(\mathrm{Xu}$, Buhalis, Weber, 2017; Xu, Tian, Buhalis, Weber, Zhang, 2016) and create positive attitudes or changes in attitude towards the organizations (sponsors) related to the app ( $\mathrm{Wu}$, Stilwell, 2018). They could also impact the forming of public opinion and attitude by shared experience, recommendations and advocacy on social networks (Wu, Stilwell, 2018; Xu, Tian, Buhalis, Weber, Zhang, 2016; Yang, Asaad, Dwivedi, 2017).

A high level of agreement is stated in terms of deeper engagement and commitment (including co-creation of services) and the effect on the experiences of tourists in the destination resulting in higher satisfaction (Sever, Sever, Kuhzady, 2015; Xu, Buhalis, Weber, 2017; Xu, Tian, Buhalis, Weber, Zhang, 2016; Yang, Asaad, Dwivedi, 2017). The involvement in a gamified local product may also impact the behavior of users and affect a decision to re-visit or visit other attractions in the destination (Yang, Asaad, Dwivedi, 2017).

In terms of branding, the informants support the possibility of using the apps for brand positioning of the destination or of suppliers by displaying the logo and by interactive advertisements (Hofacker, De Ruyter, Lurie, Manchanda, Donaldson, 2016; Sever, Sever, Kuhzady, 2015; Wu, Stilwell, 2018; Xu, Tian, Buhalis, Weber, Zhang, 2016; Yang, Asaad, Dwivedi, 2017), but also for increasing brand awareness by sending brand messages and provoking an emotional connection (Sever, Sever, Kuhzady, 2015; Xu, Buhalis, Weber, 2017; Xu, Tian, Buhalis, Weber, Zhang, 2016; Yang, Asaad, Dwivedi, 2017), and for catalyzing the brand, product or service loyalty (Sever, Sever, Kuhzady, 2015; Xu, Buhalis, Weber, 2017; Xu, Tian, Buhalis, Weber, Zhang, 2016; Yang, Asaad, Dwivedi, 2017).

At the same time, the opinion of the key informants regarding the possible benefits of using gamification apps to promote Sofia as a tourist destination goes beyond the promotional element of the marketing mix. Two aspects especially should be mentioned. First, the development of location-based gamification apps could enhance product development. In this respect different thematic routes could be suggested, past-future connections, and new forms and ways of interaction with the past could be made to attract motivated tourists resulting in a longer and deeper engagement with the destination creating a new type of experience that would otherwise be inaccessible. The capital will benefit from the socialization of lesser known and exploited cultural landscapes, leading to diversification of the tourist product and the enhancement of cultural tourism. Secondly, the spatial aspect of tourism development in the city could also be impacted by a more even distribution of tourists, not only in the central part of the city but also in peripheral and nearby destinations (e.g. including Sofia Holy Mount). 
The major limitations of the study are the sample of informants and that the period for the survey overlapped the COVID-19 pandemic. The key stakeholders in the tourism industry, including the interviewed informants, were differently affected by the pandemic situation and this influenced the results obtained. As stated, locationbased gamification apps demand the presence of tourists on site, while COVID-19 changed the priorities and concerns of the main stakeholders. We believe that the survey should be continued after the normalization of the situation and the renewal of tourist visits. Desk research on mobile apps considered only those on iOs and Android, excluding other platforms. A comparative analysis of the apps discussed is also limited due to their recent launch and the lack of enough evidence from a consumer point of view and an assessment of intrinsic motivation.

The pilot testing proved the workability of the questionnaire but raised an issue of the appropriateness of key informants. Although they were specially selected to be knowledgeable on the topic and fulfilled the rest of the criteria, less than half of them were informed about existing gamification apps and had personal impressions of even one of them. This is the main limitation of the obtained results. Nevertheless, it should be noted that only a small part of the results are presented in this article and a detailed analysis will be very useful for the future research, as well as for the development, management and promotion of locationbased gamification apps.

\section{CONCLUSION}

The investigated location-based gamification apps have a common business model of partnership and expansion of the partner network at the destination by recruiting local game creators/storytellers (including locals and tour guides or legal entities including tour operators and tourism organizations). A single tourist destination can have multiple gamified tours/trails/quests. What these location-based gamification apps have in common is independent freedom of movement, an individual pace for discovering/conquering challenges, the ability to choose a thematic axis while in the complexity of the quiz, and the combination of usefulness and enjoyment as an opportunity to learn something new. Appropriate targeting and marketing of the app itself is vital for successful implementation at destination level.

It is worth pointing out the limitation that the success of the app is not directly correlated with the attractiveness of a destination or the attractions involved. The rich history and presence of interesting little-known sites and facts, integrated into quizzes, are not enough preconditions for enhanced tourist experience. Other factors such as the non-functional requirements of the app, how end-users perceive the product, and how they interact with the product and the product's features (user interface and user experience) can have a positive or negative impact and influence its success.

In conclusion, the location-based gamification apps for the promotion of Sofia as a tourist destination are considered as a new, little-known and under-used marketing tool with moderate to high future potential, especially for the deeper engagement of users and for raising awareness of the destination.

The theoretical contribution of the article appears in the identification of three emerging and underresearched areas nationally and abroad: 1) the initiative and leading role of local authorities for the development of gamified apps at destination level; 2) the development of gamification apps as independent products converting unrevealed local resources into marketable attractions; 3) the possibility of gamification apps to be used as a tool for spatial de-concentration and management of tourist flows.

The management implications are not limited to Sofia as a tourist destination. Gamification apps can 1) be an essential part of destination management; 2) create added value, awareness and recognition of a destination's tourist resources; 3) be a useful management solution for urban public areas in terms of the spatial concentration of tourists. For Sofia, as a capital city, the local authorities are recognizing the power of gamification apps, and they are already supporting and funding such initiatives and partnerships. On the other hand, there is limited and restrictive recognition among the business sector and other local stakeholders which should not be underestimated as it is needed as a basis for successful partnership and emerging business models for destination development.

\section{REFERENCES}

About Questo (2021). Retrieved from: https:/questoapp.com/about (24.01.2021).

Chapman, A., Light, D. (2016). Exploring the tourist destination as a mosaic: The alternative lifecycles of the seaside amusement arcade sector in Britain. Tourism Management, 52, 254-263. https://doi.org/10.1016/j.tourman.2015.06.020

Correa, C., Kitano, C. (2015). Gamification in tourism: Analysis of Brazil Quest Game. e-Review of Tourism Research, 6, 1-5.

Deci, E.L., Ryan, R.M. (1985). Cognitive evaluation theory. In: E.L. Deci, R.M. Ryan, Intrinsic motivation and self-determination in human behavior. Perspectives in social psychology (pp. 43-85). Boston: Springer. https://doi.org/10.1007/978-1-4899-2271-7_3

Deterding, S., Dixon, D., Khaled, R., Nacke, L. (2011). From game design elements to gamefulness: Defining "gamification". In: MindTrek '11: Proceedings of the 15 th international academic MindTrek conference: Envisioning future 
media environments (pp. 9-15), September 2011. https://doi. org/10.1145/2181037.2181040

Discover Sofia (2021). Retrieved from: https://www.secretcitytrails.com/product-category/discover-sofia/ (12.01.2021).

Groh, F. (2012). Gamification: State of the art definition and utilization. In: Proceedings of the $4^{\text {th }}$ seminar on research trends in media informatics (pp. 39-46). 14 $4^{\text {th }}$ February 2012.

Hofacker, C.F., De Ruyter, K., Lurie, N.H., Manchanda, P., Donaldson, J. (2016). Gamification and mobile marketing effectiveness. Journal of Interactive Marketing, 34, 25-36. https:// doi.org/10.1016/j.intmar.2016.03.001

Maan, J. (2013). Social business transformation through gamification. International Journal of Managing Information Technology, 5 (3), 9-16. https://doi.org/10.5121/ijmit.2013.5302

Marinov, V. (2005). Partners for development. Partnership model for strategic planning of local development. Sofia: ECIP.

Marinov, V. (2012). Key informants' analysis of small scale tourism development in mountain villages. In: SEEmore conference: Mountain resources and their response to global change (abstracts) (pp. 27-28). Ankara University, Turkey.

Marinov, V., Dogramadjieva, E., Assenova, M., Petkova, E., Baikov, B. (2015). Tourism product development and marketing of Sofia metropolitan area: Business perceptions and priorities. In: I. Tózsa, A. Zátori (eds), Metropolitan tourism experience development (pp. 51-67). Budapest: Corvinus University of Budapest.

Marshal, M.N. (1996). The key informant technique. Family Practice, 13 (1), 92-97. https://doi.org/10.1093/fampra/13.1.92

Negruşa, A.L., Toader, V., Sofică, A., Tutunea, M.F., Rus, R.V. (2015). Exploring gamification techniques and apps for sustainable tourism. Sustainability, 7 (8), 11160-11189. https:// doi.org/10.3390/su70811160

Neuhofer, B., Buhalis, D., Ladkin, A. (2012). Conceptualising technology enhanced destination experiences. Journal of Destination Marketing E Management, 1 (1-2) , 36-46. https:// doi.org/10.1016/j.jdmm.2012.08.001

Nexto (2021). Retrieved from: https://nexto.io/ (13.01.2021).

Schell, J. (2008). The art of game design: A book of lenses. Pittsburgh: CRC Press.

Seaborn, K., Fels, D.I. (2015). Gamification in theory and action: A survey. International Journal of Human-Computer Studies, 74, 14-31. https://doi.org/10.1016/j.ijhcs.2014.09.006
Secretcitytrails (2021). Retrieved from: https://www.secretcitytrails.com/ (12.01.2021).

Serdica Riddles (2021). Retrieved from: https://www.facebook. com/SerdicaRiddles/ (21.01.2021).

Sever, N., Sever, G., Kuhzady, S. (2015). The evaluation of potentials of gamification in tourism marketing communication. International Journal of Academic Research in Business and Social Sciences, 5 (10), 188-202. https://doi.org/10.6007/IJARBSS/ v5-i10/1867

Swacha, J., Ittermann, R. (2017). Enhancing the tourist attraction visiting process with gamification: Key concepts. Engineering Management in Production and Service, 9 (4), 59-66. https://doi. org/10.1515/emj-2017-0031

Weber, J. (2014). Gaming and gamification in Tourism: 10 ways to make tourism more playful. Retrieved from: https://www.thinkdigital.travel/ (1.03.2021)

Wu, L., Stilwell, M.A. (2018). Exploring the marketing potential of location-based mobile games. Journal of Research in Interactive Marketing, 12 (1), 22-44. https://doi.org/10.1108/ JRIM-06-2017-0041

Xu, F., Buhalis, D., Weber, J. (2017). Serious games and gamification of tourism. Tourism Management, 60, 244-256. https://doi. org/10.1016/j.tourman.2016.11.020

Xu, F., Tian, F., Buhalis, D., Weber, J., Zhang, H. (2016). Tourists as mobile gamers: Gamification for tourism marketing. Journal of Travel and Tourism Marketing, 33 (8), 1124-1142. https://doi. org/10.1080/10548408.2015.1093999

Xu, F., Weber, J., Buhalis, D. (2014). Gamification in tourism. In: Z. Xiang, I. Tussyadiah (eds), Information and communication technologies in tourism (pp. 525-537). Cham: Springer. https:// doi.org/10.1007/978-3-319-03973-2

$\mathrm{Xu}$, Y. (2012). Literature review on web app gamification and analytics. Honolulu: University of Hawaii. Retrieved from: https:// citeseerx.ist.psu.edu/viewdoc/download?doi=10.1.1.462.5228 \&rep=rep1\&type=pdf (1.03.2021)

Yang, Y., Asaad, Y., Dwivedi, Y. (2017). Examining the impact of gamification on intention of engagement and brand attitude in the marketing context. Computers in Human Behavior, 73, 459-469. https://doi.org/10.1016/j.chb.2017.03.066

Zichermann, G., Cunningham, C. (2011). Gamification by design: Implementing game mechanics in web and mobile apps. Sebastopol: O’Reilly Media Incorporated. 